\title{
LA EXPERIENCIA DE LA MATERNIDAD EN EL CORAZÓN DE LAS \\ TINIEBLAS BRASILEIRAS
}

Elizabeth Tamara Hutnik

Universidad de Buenos Aires

ehutnik@gmail.com

Recibido: 23-02-2011

Aceptado: 01-04-2011

\section{Resumen}

A partir del trabajo antropológico de Nancy Scheper-Hughes, el presente ensayo explora las dimensiones personales y existenciales del amor materno y la muerte infantil en Alto do Cruzeiro, barrio cercano al pueblo comercial de Bom Jesús, en el estado de Paraíba, al nordeste de Brasil. La conformación de una subjetividad femenina en una situación de extrema pobreza presenta a las mujeres de este grupo como dotadas de un sistema emocional alternativo, atravesado por procesos locales y transnacionales de corte político y económico. La naturaleza de las emociones es cuestionada, como así también el establecimiento de los lazos familiares de corto, medio y largo plazo.

Palabras clave: Amor materno, muerte infantil, emoción.

\begin{abstract}
Considering Nancy Scheper-Hughes anthropological fieldwork, this paper explores the personal and existential dimensions of maternal love and child death in the Alto do Cruzeiro neighbourhood, near the city of Recife, in the northeast of Brazil. The feminine subjectivity conformation in an extreme poverty context presents this group of Brazilian women as holders of an alternative emotional system, which is influenced by both local and global processes in political and economic terms. The nature of emotion is questioned, and so is the construction of short, medium and large period of time.
\end{abstract}

Key words: Maternal love, child mortality, emotion. 


\title{
1. Introducción
}

\begin{abstract}
"Hay una imagen clásica entre las que simbolizan el cuidado en el mundo occidental moderno: el retrato de una madre con su hijo en brazos. La madre que aparece allí suele estar en su casa sentada en un sillón, o en un escenario de ensueño, como un jardín. Impresa a menudo en anticuadas tarjetas de cumpleaños y en los anuncios publicitarios de lana que aparecen en revistas para mujeres, la imagen es una versión secular y de clase media de la Madona con su Hijo. Quien brinda cuidado en ella no es un hombre, sino una mujer. No está en un lugar público, sino en su casa. Además, el cuidado que se retrata parece un acto natural, que no requiere esfuerzo. La mujer está sentada, quiescente, no parada ni en movimiento (posiciones asociadas con el "trabajo"). Parece disfrutar del cuidado que brinda a su hijo, y el rostro del hijo a menudo sugiere que la madre es buena en la tarea de cuidarlo. De este modo, la imagen del cuidado se vincula con cosas femeninas, privadas y naturales que funcionan bien, a la vez que evoca un determinado ideal" (Hochschild, 2008: 307).
\end{abstract}

El ideal descrito en el epígrafe de Arlie Hochschild aparece completamente subvertido entre las mujeres del barrio del Alto do Cruzeiro, en la región de Bom Jesus da Mata, estado de Paraíba al nordeste de Brasil. Allí, el amor materno está ligado de manera indisociable a la muerte infantil.

A través de la exploración de los distintos significados, creencias, sentimientos y prácticas de la maternidad que configuran un determinado tipo de moralidad femenina, la antropóloga Nancy Scheper-Hughes (1993) arriesga una hipótesis polémica en su libro Death without weeping. The violence of everyday life in Brazil ${ }^{1}$ : existe una conformación alternativa del amor maternal, moldeado por dificultades económicas acuciantes y obligaciones culturales. El desarrollo o construcción del amor maternal se da una vez que el riesgo de la pérdida del hijo ha pasado. Previamente, los cuidados maternos; que desde una mirada occidental de clase media son concebidos como un acto natural; dejan lugar al trato distante, la indiferencia, el desprendimiento filial e incluso, el abandono.

La investigación etnometodológica es llevada a cabo en dos etapas: a mediados de la década del 60 y a fines de los 80. En ambos momentos la autora recolectó información sobre las familias, la historia reproductiva, las migraciones, los arreglos conyugales y los hijos de 100 mujeres semianalfabetas del Alto. Si bien se propone como disciplina de trabajo la Antropología, la autora intenta explícitamente desprender dicho abordaje de los presupuestos morales occidentales en la observación de las instituciones culturales y las prácticas asociadas a ellas. El rol del antropólogo-

\footnotetext{
${ }^{1}$ En castellano La muerte sin llanto. Violencia y vida cotidiana en Brasil, Barcelona: Ariel., 1997.
} 
investigador es puesto en conflicto y su presencia en el campo se problematiza a partir de la tensión antropóloga - compañera (como llamaban a la investigadora el resto de las mujeres de la comunidad). La exploración del campo es activa y comprometida, producto del marco de conocimiento y del espacio de tensiones en el que se inscribe Scheper-Hughes.

\section{Escribir la experiencia}

"[...] no nos avergonzamos de mantener fija la mirada en lo inenarrable. Aun a costa de descubrir que lo que el mal sabe de sí, lo encontramos fácilmente también en nosotros" (Agamben, 2000: 32).

La experiencia que las mujeres del Alto experimentan se ubica en tierras cercanas a lo indecible. ¿Cómo escribir la experiencia, entonces, sin que las palabras se arrojen a una especie de principio de incertidumbre? ¿Cómo articular una sintaxis desde la imposibilidad cuando hay una fractura entre la palabra y la cosa? ¿Cómo nombrar el mundo si el mundo parece ser incomprensible? ¿Cómo representar la alteridad cuando ciertos acontecimientos provocan una ruptura devastadora? Nancy Scheper-Hughes propone, en lugar de instalarse en posturas juiciosas y distantes, establecer un pacto con el lector para dar voz a esas mujeres que circulan día a día en el corazón de las tinieblas brasileiras.

El espacio de escritura de la antropóloga es el de la resistencia: escribir contra el terror, como sugiere Taussig (1989). De este modo, Scheper-Hughes escribe desde la experiencia, sin distancia narrativa y vagando por una pluralidad genérica que va del diario de viaje a la reflexión moral; del texto político al storytelling. Mediante esta apelación a la multiplicidad realiza una construcción dialógica (Bajtin, 1998) del conocimiento antropológico, pues se produce una suerte de hermandad o reconocimiento con su sujeto de estudio.

Death without weeping (1993) nos confronta con distintos significados, creencias, sentimientos y prácticas de la maternidad que cuestionan la moralidad femenina tradicional, pero también la de una comunidad civil en su conjunto. En el Alto do Cruzeiro se da una conformación alternativa del amor maternal moldeado por las dificultades económicas acuciantes y las obligaciones culturales enraizadas desde hace décadas en este grupo social. Las historias de vida repiten a menudo un patrón: las mujeres tienen varias parejas -legítimas y no legítimas- a lo largo de su vida 
reproductiva y los hijos son una constante no controlada en ese derrotero. La realidad socioeconómica obliga a las familias a vivir en contextos de extrema pobreza y aislamiento, sin asistencia social ni estatal de casi ninguna clase. Dado este escenario hostil para la supervivencia y bienestar de madre e hijo, los efectos de la deprivación de amor y el alimento son prácticas habituales entre las madres brasileras de la región. También es tradicional la integración e interrelaciones fuertes entre miembros de la comunidad. De ahí la responsabilidad compartida sobre la vida de los hijos. Los lazos de parentesco y compadrazgo constituyen modos intersubjetivos de experimentar la realidad (Leinaweaver y Seligmann, 2009). Esta conectividad social genera lazos aditivos y no sustitutivos en el cuidado infantil pues, como sugiere Van Kleet (2009) las redes de parentesco de sangre y espirituales funcionan como un entramado de contención económico-social. En efecto, la comunidad del Alto do Cruzeiro establece mecanismos de cuidado compartido de los hijos, organizados sobre una estructura principalmente femenina. Las comadres, las parteras y las colegas tienen una autoridad importante al interior del seno familiar. En algunas ocasiones sus opiniones pueden ser incluso más significativas para la madre que la voz del padre. El rol masculino asociado tradicionalmente a la ley se presenta subsumido frente al papel de la comunidad.

Si tal como plantea Blanchot (1992) escribir es hacerse eco de lo que no puede dejar de hablar, Scheper-Hughes intenta ocupar el lugar incómodo y descentrado que la relaciona con el mundo, con su campo de trabajo y consigo misma. La escritura como mediación permite que el lenguaje funcione como imagen, como imaginario y como traducción de lo que parece ser inenarrable. Escribir es aquí un modo de intervención para que en este relato tome forma, coherencia y sentido lo que experimentan las madres del Alto do Cruzeiro.

\section{Narrar la experiencia}

En la narración de las muertes infantiles donde el amor maternal es puesto en cuestión desde una mirada externa, uno de los factores que interviene es la presunta confusión entre causalidad y culpa. Si bien es verdad que las mujeres del Alto do Cruzeiro deben enfrentarse a elecciones morales que una madre no debería tener que hacer, la aparente ausencia de dolor, duelo, trauma o shock es leída como indiferencia. De acuerdo con el principio común de Winnicott (1998) de la madre devota que subyace a toda idea del amor maternal universal, estas mujeres calmas y resignadas frente a lo 
que no puede modificarse aparecen como figuras monstruosas, aberrantes e insensibles. Sin embargo, sus relatos dan cuenta de un contexto geofísico de peligro y contingencia determinantes: agua contaminada, tierra arenosa como suelo de las casas, insectos, serpientes en las márgenes del ríos, Chagas, animales sueltos, gusanos en las letrinas, leche y carne no refrigeradas, etc.

Tal como sucedía en el Ospedale degli Innocenti ${ }^{2}$ en 1419 en Florencia, no hay estigma en abandonar un angelito (en adopción o a la muerte) si las condiciones no están dadas para que sobreviva. En esta instancia la autora presenta dos verbos contrapuestos empleados por las madres que servirán para clarificar sus conductas. Por un lado, una madre puede aferrarse (hold) al hijo. Esta opción suele darse una vez que el peligro de muerte ha pasado, el niño ha crecido y ha probado ser digno de pertenecer a la familia y recibir sus cuidados. Aquí es interesante notar el patrón de apelación del niño. Mientras que el recién nacido carece de unicidad y muchas veces recibe un nombre de otro $\mathrm{u}$ otros miembros de la familia; el hijo mayor, fuerte y desarrollado es aquel que vive lo suficiente para hacerse, metonímicamente, de un nombre. Su denominación, que muchas veces es un apodo producto de una marca física o de personalidad, sella los lazos amorosos de la familia hacia el/la joven. Tal como lo indica la locución latina nomen omen, el nombre es un presagio, en el nombre se esconde el destino de la persona que, ahora sí, podrá ser distinto a la muerte. Pero por otro lado una madre también puede dejar ir al hijo (to let go) y es en este gesto que es preciso realizar un salto de fe.

"La fe consiste en la paradoja de que el Particular se encuentra como tal Particular por encima de lo general, y justificado frente a ello, no como subordinado sino como superior. Esta situación no admite la mediación, pues toda mediación se produce siempre en virtud de lo general. [...] La historia de Abraham ilustra una suspensión teleológica de lo ético" (Kierkegaard, 1995: 123).

Según la lectura de Kierkegaard a partir del episodio del Antiguo testamento que somete a Abraham a un dilema ético, Abraham lleva a cabo dos movimientos. Por un lado tiene el gesto de la resignación infinita al renunciar a su hijo Isaac (lo que nadie puede comprender porque se trata de una empresa privada), y a su vez, lleva a cabo el movimiento de la fe, pues ese es su consuelo. Paralelamente, las madres del Alto permiten a la naturaleza seguir su curso natural al cooperar con el plan de dios y

${ }^{2}$ El Hospital de los Inocentes fue un orfanato de niños de Florencia diseñado por Filippo Brunelleschi. Encima de cada columna hay un tondo cerámico. El diseño realizado por Andrea della Robbia representa a niños en pañales sobre fondo azul, indicativo del torno donde podían abandonarse los bebés no deseados por sus madres. 
guardarse en la normalidad del mutismo y la apatía.

"Abraham calla porque no puede hablar, es ahí donde residen la angustia y la miseria. [...] Ese es el caso de Abraham: lo puede contar todo, pero hay una cosa que no puede decir, y al no poder decirla, o sea, al no poder decirla de modo que el otro pueda comprender, no habla" (Ibíd., pp. 197-198).

Esta cultura del silencio no se trata, tal como sugiere Gulati (1999), de evitar hablar de ciertos temas por urbanidad, sino de tomar la honrosa determinación de guardarse el verdadero dolor para sí mismo ${ }^{3}$. Si bien estas mujeres brasileras cuentan con el aval de su comunidad, todo aquel que no pertenece a su grupo social juzga y no comprende.

"No hubo nadie capaz de comprender a Abraham. [...] Aquel que ama a Dios no necesita de las lágrimas ni de la admiración; por amor olvida su sufrimiento, sí, y los olvida tan absolutamente que no quedaría tras él ninguna huella de su dolor, si no fuese el mismo Dios quien viene a recordárselo [...]" (Íbid., pg. 205).

Scheper-Hughes viene a recordarles la pérdida mediante una batería de preguntas y una vida en común que aproxima al investigador con su sujeto de estudio. Enfrentadas con el pedido de una narración, las madres componen un sistema metafórico rico en comparaciones naturales y religiosas, fuertemente determinado por la propia lengua. De este modo, los niños son como pájaros que están hoy y vuelan mañana, los bebés quieren escaparse de la vida como ángeles visitantes y los pequeños querubines cuyas vidas son como velas ardientes que en cualquier momento se apagarán. Estos niños son difíciles de criar por vivir en continua mengua. Se reducen con cada respiro causado por diversas dolencias de infancia o, como las madres lo llaman: "ataques de niños", que se asocian a enfermedades de las que parece haber entre 14 y 21 variantes. La mayoría de los síntomas son muy comunes en la infancia: molestias de dentición, diarreas, erupciones cutáneas, marcas de nacimiento, irritabilidad, vómitos, convulsiones.

Una de las claves para entender la muerte sin llanto tiene asidero en la propia lengua. Muchas de las mujeres suelen construir el campo semántico posterior a la muerte de un bebé en torno a la noción de saudade (en portugués define una emoción vinculada a la melancolía). La saudade es una suerte de nostalgia ligada a la ausencia y la pérdida, pero que no supone necesariamente la depresión, la angustia y la pena. Estas tres sensaciones son descriptas por las madres como emociones negativas, producto de

\footnotetext{
${ }^{3}$ Es interesante la relación con el film de Philippe Claudel, (2008), "Il y a longtemps que je t'aime".
} 
recuerdos amargos. La saudade, en cambio, se vincula con el hecho de extrañar. Es un término que, según la autora, no puede tener una traducción precisa pues es la expresión del ser brasilero.

Una vez más, Scheper-Hughes pone en evidencia la inadecuación de las nociones modernas occidentales burguesas como: maternal bonding (Klaus y Kennell, 1996); maternal thinking (Ruddick, 1989); personalidad femenina (Chodorow, 1979); ya que todas ellas establecen una norma cultural como general o universal, alienando experiencias alternativas como la del Alto do Cruzeiro. No obstante, hay dos categorías analítico-descriptivas aparentemente causales que juegan un rol central en el análisis de campo: doomed babys y child neglect. Ciertos bebés están "condenados" a un destino trágico, de manera similar a la concepción latina del fatum. Es esa fatalidad -y no una decisión inhumana de la madre- la que sugiere que el abandono es lo más recomendable en situaciones en las que el niño no desea vivir. Estos bebés condenados son angelitos o pequeños visitantes no miembros permanentes de la familia a los que, en general, no vale la pena salvar, pues traerán futuros disgustos y sufrimiento a la familia. Siguiendo a Van Kleet (2008), el abandono del niño puede aliviar la presión de una familia numerosa, con muchas bocas que alimentar. En consecuencia, el descuido o negligencia puede tomar varias formas: falta de alimento, ausencia de asistencia médica, entrega en adopción o préstamo temporal.

\section{Interpretar la experiencia}

“Don't pity the infants who died here on the Alto do Cruzeiro. Don't waste your tears on them. Pity us instead. Weep for their mothers who are condemned to live" (ScheperHughes, 1993: 408).

El trabajo de Scheper-Hughes pone en juicio la noción del amor maternal como una emoción natural. “Cabe aclarar que por 'emoción' me refiero a la conciencia de la cooperación corporal con una idea, un pensamiento o una actitud [...]" (Hochschild, 2008: 111). Así, toda una matriz histórica de imágenes, significados, sensaciones y prácticas socio-culturales resultan cuestionadas. La hipótesis en juego plantea que permitir e incluso contribuir a la muerte de un hijo no es una práctica inhumana o nonatural, sino más bien una respuesta razonable frente a obligaciones y contingencias norazonables. La cultura y la escasez, tanto material como psicológica, tienen fuertes efectos morales y prácticos sobre el pensamiento maternal (Ruddick, 1989). Lo que se 
desprende del análisis es que el ideal del amor definido en la literatura sociológica, psicológica e histórico social no es universal e innato, sino una representación ideológica asentada en las condiciones materiales que determinan la vida reproductiva de las mujeres. En el caso de las mujeres del Alto, ellas pertenecen a un grupo que podría clasificarse como pre-moderno, y presentan una conformación alternativa del amor maternal ([m]other loves), moldeado por dificultades económicas acuciantes y obligaciones culturales arraigadas en la comunidad por generaciones. Por ende, su patrón de moralidad no sigue la sabiduría convencional o dominante en términos de justicia y equidad, sino que se rigen por la ética del bote salvavidas (Hardin, 1974). La distancia, la indiferencia, el desprendimiento mortal e incluso el abandono se explican a partir de una construcción diversa de la corporeidad, el yo, y la propia identidad.

Ahora bien, no podemos negar que el amor maternal existe en el Alto do Cruzeiro, pero su desarrollo o aparición se da una vez que el riesgo de la pérdida del hijo ha pasado. Antes de este momento, la habilidad de confrontar la muerte genera conductas maternales estoicas y ecuánimes que tienen relación directa con los patrones de alimentación que, en su extremo, terminan en el abandono mortal o abandono benigno (Cassidy, 2007), noción más cercana a la autopercepción que tienen las mujeres sobre sus actos. No hay duelo como consecuencia de esta suerte de eutanasia pasiva ya que las causas de muerte tienen más que ver con una deficiencia en el niño y no una desatención maternal. Además, no es sólo la madre quien determina la pulsión vital del recién nacido $-\mathrm{y}$ su potencial sentencia de muerte- sino también la partera que actúa en representación de la comunidad y sus costumbres.

"La maternidad es una experiencia compleja con aspectos positivos y negativos, la madre es sujeto de su experiencia, [...] la actuación de las madres no está prefijada y no puede analizarse fuera de la historia y el contexto socio-cultural” (Blanco, 2000: 8-9).

Por estos motivos no existe la estigmatización social, ni marginación, y mucho menos, el enjuiciamiento. Juzgar inapropiado o incorrecto el proceder de estas mujeres supone realizar elaboraciones de la emoción de manera externa. Más precisamente, supondría reproducir lo que Arlie Hochschild (2008) llama adecuación moral, donde lo que importa es lo que es legítimo desde el punto de vista moral. Evaluar la adecuación de una emoción supone cotejarla con una situación real, no abstracta, gracias a la que el evaluador puede obtener un criterio de normalidad alejándose de posibles distorsiones personales o subjetivas. Pero la actividad emocional carece de patrones fijos y de hecho, se vuelve impredecible.

En otras palabras, la construcción de la emoción es cultural (al tiempo que 
política y económicamente condicionadas), no natural y colectiva. Siguiendo a Hochschild (1979), la mujer brasilera -al igual que la mujer norteamericana- produce sentimientos que responden a agendas políticas ocultas. La emoción, la retórica de la maternidad, del amor maternal y de su ausencia son entendidas como un constructo privado y público-ideológico, simultáneamente. Desde un registro mercantilista, de los que abundan ejemplos en países europeos desarrollados, la concepción moderna del amor maternal se acerca a una nueva estrategia reproductiva: criar pocos hijos equivale a una inversión emocional y material. Tal como se plantea en el trabajo de Leinaweaver y Seligmann (2009), esta estrategia se vincula con la escasez de bebés en el primer mundo. Una de las formas que puede adquirir esta inversión tiene que ver con la implementación de adopciones transnacionales, o adopciones en los márgenes (Van Kleet, 2009). En este caso, las agendas políticas suponen la construcción de un complejo sistema de políticas estatales y brokers de adopción transnacional que, en muchos casos, dibujan escenarios -legales e ilegales- signados por dudosas moralidades, intereses económicos y presunciones no transparentes. También aquí el proceso de constitución familiar es dificultoso y se asienta en claras inequidades entre países creadores y receptores de niños que, una vez más, son tratados como no-personas (Leinaweaver y Seligmann, 2009).

\section{Conclusiones}

El sistema de educación espartano se organizaba a partir de la selección eugenésica de la progenie. Una comisión de ancianos espartanos irrumpían el seno de todas las familias del clan (cualquiera fuera su status social) y examinaban a los pequeños recién nacidos para evaluar su conformación física. Si el bebé presentaba signos de debilidad o poca vitalidad, se lo consideraba una carga para toda la comunidad y debían deshacerse de él. De este modo, se le conducía al Apótetas, que era el fondo de un barranco y un lugar de abandono, al pie del monte Taigeto, donde se le arrojaba para morir. (Jeanmaire, 1939).

Todas las sociedades a lo largo de la historia han tenido sistemas de valores asociados a la familia y al amor filial. Cuidar a un hijo supone un vínculo emocional, habitualmente recíproco entre quien brinda el cuidado y quien lo recibe. La primera suele ser responsable por el bienestar del más indefenso. Las dos variables en juego son, entonces, responsabilidad e interés. 
Desde una perspectiva cercana a la sociología de las emociones el libro de Nancy Scheper-Hughes, Death without weeping, presenta una realidad extrema. Dejar morir un hijo en el Alto do Cruzeiro es un acto que las madres perciben como compasivo. No se trata de ausencia de emoción sino de una suerte de amor empático que debe negociarse frente a la debilidad y la convalecencia infantil. Este enfoque analiza qué y cómo pensamos en relación con las emociones y los sentimientos (entendidos por la misma autora como emociones más suaves). La conducta es entonces parte de una norma culturalmente dirigida y el dejar morir a un hijo es una práctica no autonómica, sino socialmente producida y condicionada por la contingencia del entorno, entendiendo por éste el contexto político, económico y religioso, en un determinado tiempo y espacio. Lo verdadero en relación con las emociones puede tener, de acuerdo a Hochschild (2008: 140), una explicación interaccionista:

\begin{abstract}
"[...] las experiencias sociales penetran la emoción con mayor insistencia, con mayor efectividad y en más coyunturas. [...] los factores sociales influyen en la provocación y en la expresión de las emociones, pero desde esta perspectiva también guían nuestra manera de etiquetar, interpretar y manejar las emociones. Ahora bien ies posible establecer regulaciones frente al sistema emocional? ¿Es este sistema verdaderamente cognoscible? ¿Cómo se vuelve un parámetro de intercambios sociales? En la comunidad del Alto do Cruzeiro ¿logran las mujeres 'elaborar' sus emociones? [...] 'elaborar' una emoción o un sentimiento es lo mismo que 'manejar' una emoción o llevar a cabo una 'actuación profunda'. Nótese que la elaboración de los sentimientos se refiere al esfuerzo - al acto de intentar- y no al resultado, que puede o no lograr su cometido".
\end{abstract}

Al alcance de estas mujeres sólo está el presente de privaciones de sus hijos, no su futuro. Finalmente, la realidad de una relación materno-filial es extraordinariamente difícil de conocer.

Las madres del Alto son responsables del cuidado de sus hijos y se interesan por ellos. En sus manos, sin embargo, no siempre está la salvación. Muchas veces la decisión de la madre sólo se reduce al modo en el que el niño ocupará su lugar dentro de la familia. Y muchas veces, el camino se asemeja al ritual del chivo expiatorio: el pequeño pagará las culpas de la gran mayoría, librando a toda la comunidad de posibles cargas y represalias futuras. Nadie debe llorar por el inocente perdido pues, según la superstición brasilera, las lágrimas no deben humedecer el camino del ángel ni mojar sus alas. 


\section{BIBLIOGRAFÍA}

- Agamben, G. (2000): Lo que queda de Auschwitz. Valencia: Pretextos.

- Bajtin, M. M. (1998): Estética de la creación verbal. México: Siglo XXI.

- Blanchot, M. (1992): El espacio literario. Barcelona: Paidós.

- Blanco, A. I. et al. (coord.) (2002): Nuevas visiones de la Maternidad, León: Universidad de León.

- Cassidy, C. (2007): Thinking children. Londres: Continuum Internacional.

- Chodorow, N. (1979): The reproduction of mothering. Los Angeles: University of California Press.

- Gulati, L. (1999): “The tyranny of tradition”. En Indian Journal of Gender Studies 6, $\mathrm{n}^{\mathrm{o}} .2$, pp. 185-201.

- Hardin, G. (1974): "Lifeboat Ethics: the Case Against Helping the Poor". En Psychology Today, $\mathrm{n}^{\circ}$. 8, pp. 38-43.

- Hochschild, A. (1979): "Emotion work, feeling rules, and social structure”. En American Journal of Sociology, $\mathrm{n}^{\circ}$. 85, pp. 551-575. . (2008): La mercantilización de la vida íntima. Madrid: Katz editores.

- Jeanmaire, H. (1939): Couroi et Courètes: essai sur l'éducation spartiate et sur les rites d'adolescence dans l'Antiquité hellénique. Lille: Bibliothèque universitaire.

- Kierkegaard, S. A. (1995): Temor y temblor. México: Fintamara.

- Klaus, M. y Kennell, J. (1996): Bonding. Massachussets: Addison-Wesley.

- Ruddick, S. (1989): Maternal thinking: Toward a politics of peace. Boston, MA: Beacon Press.

- Leinaweaver, J. B. y Seligmann, L. (2009): "Introduction: Cultural and Political Economies of Adoption in Latin America". En The Journal of Latin American and Caribean Anthropology. vol. 14, pp. 1-19.

- Scheper-Hughes, N. (1993): Death without weeping. The violence of everyday life in Brazil. California: University of California Press.

- Taussig, M. (1989): "History as commodity in some recent American (anthropological) Literature”. En Critique of Anthropology, vol. 9, n. 1, pp. 7-23.

- Van Kleet, K. (2008): Performing kinship: Narrative, Gender and the Intimacies of Power in the Bolivian Andes. Austin: University of Texas Press.

. (2009): "We had already come to love her: Adoption at the margins of the Bolivian

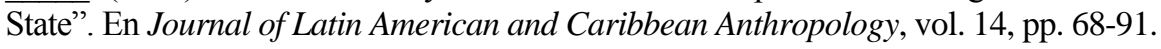

- Winnicott, D. W. (1998): Los bebés y sus madres. Barcelona: Paidós. 